\title{
PERFECTIONISM: RESOURCE OF PATHOLOGY
}

\author{
Inese Jokste \\ Rīga Stradiņš University, Latvia
}

\begin{abstract}
The main trait differing perfectionists from other individuals is high standards, which is the unifying feature in all models. No matter how well the theories and models of perfectionism are developed, there has always been disagreement about the nature of perfectionism - is it 'The Good, the Bad or the Ugly?' The paper aims to review the studies focused on the mechanisms behind perfectionistic representation, its threats to psychological wellbeing, caused by its pathological side, and look into perfectionism as a possible resource for personal growth and achievement. In the first section of the paper, the aetiology of perfectionism is viewed to see if the foundations add to the type of perfectionism formed. In the second section, models of perfectionism are discussed to see their ability to distinguish between adaptive and maladaptive perfections. Finally, in the third section, perfectionism's positive and negative sides are discussed to understand when perfectionism becomes pathological and when it can be viewed as a resource. In the research of perfectionism, the quantitative approach is mostly used. However, the literature review provides the possibility to have an overview of current knowledge on the nature of perfectionism and to identify gaps in the existing research. The results show that although perfectionism may be viewed both as a positive and negative trait, its negative consequences prevail over its possible positive outcomes. Complex research involving several perfectionism measurements is needed to understand the impact of different combinations of perfectionism types on positive and negative outcomes. The findings of the literature review will serve as the theoretical background for studying perfectionism, its pathological traits, and its possible contribution to achievement.
\end{abstract}

Keywords: adaptive perfectionism; literature review; maladaptive perfectionism; negative perfectionism; pathological perfectionism; positive perfectionism; resource.

\section{Introduction}

Perfectionism had captured scientific interest since the middle of the 20th century. It was first mentioned in the works of Horney (1950), describing personality types, Adler (1956) in the context of striving for excellence, Missildine (1963) describing the early development of perfectionism and its connection to self-esteem, Maslow (1970) in the context of his self-actualisation theory and many other scientists, who have shown interest in the phenomena of perfectionism and its role in the individual's life. The first models of perfectionism looked at it mostly as a one-dimensional trait, until Hamachek (1978) proposed the idea of the duality of perfectionism, stating that perfectionism could be viewed 
as normal or neurotic, meaning that depending on its orientation, it can positively or negatively affect the development of personality. Since then the several multidimensional models of perfectionism were published (see Frost et al., 1990; Hewitt \& Flett, 1989, 1990; Smith, Saklofske, Stoeber \& Sherry, 2016) and a number of studies on perfectionism and its relationship to a variety of variables, such as depression (Hewitt \& Flett, 1990), stress (Smith, Saklofske, Yan, \& Sherry, 2017), personality traits (Cruce, Pashak, Handal, Munz, \& Gfeller, 2012) coping strategies (Gnilka, McLaulin, Ashby, \& Alle, 2017), achievement (Damian, Stoeber, Negru, \& Baban, 2014b), and many others, have increased in both general and clinical populations. The researchers are trying to look into the positive and negative sides of perfectionism and also its pathological side as perfectionism is included in DSM-5 as one of the symptoms of Obsessivecompulsive personality disorder (DSM-5, 2000). Taking into account the tendency for perfectionistic traits to increase in the last decades (Curran \& Hill, 2017), it becomes essential to understand the mechanisms behind perfectionistic representation, danger to psychological wellbeing caused by its pathological side, and to look into perfectionism as a possible resource for personal growth and achievement.

\section{Aim and Method}

The research aims to clarify mechanisms behind perfectionistic representation, its threats to psychological wellbeing and looks into perfectionism as a possible resource for personal growth and achievement. The theoretical literature review approach was used for the study purpose, as it allows to focus on a pool of perfectionism theories, positive and negative traits of perfectionism and find new theories to be tested in the future. Computerised literature searches were conducted on Scopus and Web of Science. As the terms for the search were used "perfectionism”, "positive”, "negative”, "adaptive”, "maladaptive” and "pathological” and "resource", using Boolean operators (“AND”, "OR" and "NOT"). In addition, backward citation searching was used.

Studies were included in the review if they met the following criteria: a) met the search criteria, b) were published in European countries or North America to exclude cultural differences; c) for quantitative studies as a measure of perfectionism valid and reliable approach was used, d) were published in English, e) the study was carried out in a population of adolescents and adults. The screening of the initial 72 articles was done, and 48 articles and literature sources were retrieved. 


\section{Perfectionistic Trait Formation Models}

To understand the mechanisms behind perfectionistic representation, the aspects of perfectionism formation and its connection to the type of perfectionism should be clarified. It is clear that perfectionism develops in the context of early childhood experiences with significant others (see, Missildine, 1963; Rothstein, 1991), and it involves several factors, such as family factor, response to specific child needs factors, and environmental factors (Flett, Hewitt, Oliver, \& Macdonald, 2002). As many theorists have noted, early relationships with parents, caregivers, siblings, and experienced neglect or inability to attune to child's needs play the essential role in forming perfectionistic behaviour in early childhood, as well the throughout the individual's life (e.g., Greenspon, 2008; Frost et al., 1990; Hamachek, 1978; Hollender, 1965). Perfectionism is formed as an internal model of the relationship between oneself and others, developing self-concept, basing on attachment to caregivers (Hewitt, Flett, \& Mikail, 2017).

There are two main approaches in explaining the development of perfectionism. The first approach is the Family history models proposed by Flett and colleagues (Flett, Hewitt, Oliver, \& Macdonald, 2002) and later studied in the framework of qualitative methodology (see Speirs-Neumeister, 2004; SpeirsNeumeister, Williams, \& Cross, 2009; Damian, Stoeber, Negru, \& Baban, 2013). This approach includes four models. The social expectation model is based on the sense of conditional self-worth provided by caretakers or the environment. On the other hand, the social reaction model assumes that perfectionism forms under a harsh environment (abuse, maltreatment, exposure to shame, etc.) as a coping mechanism. Perfectionistic parents' behaviour is imitated, or parents (or caregivers) are idealized in the social learning model. The anxious rearing model is less studied than previous ones. It aims to clarify the development of perfectionism as exposure to parental worry that forms overprotection and a constant reminder to avoid possible mistakes, later forming a strongly pronounced fear of mistakes.

The second approach is the Perfectionism social disconnection model (PSDM), proposed by Hewitt and colleagues (Hewitt, Flett, Sherry, \& Caelian, 2006), pointing out that interpersonal difficulties tend to form perceived social disconnection in perfectionists together with a variety of challenges: interpersonal over-sensitivity and hostility resulting in social disconnection, alienation, or a sense of not belonging.

Although the models mentioned above are based on early experiences with caregivers, it does not necessarily mean that parents should always take responsibility for perfectionistic struggles or difficulties of their children arising from this specific personality structure (Hewitt, Flett, \& Mikail, 2017). Genetics 
and cognitive neuroscience should be taken into account, suggesting that child's temperament is what mostly determines interaction with the parents and the behaviour of the parents, in turn, shapes the child's personality, meaning that the development of perfectionism forms in the interaction of child's inherent personality traits, parents' psychological characteristics and compatibility between both (Gabbard, 2004).

The models described aim to explain the development of perfectionism in early childhood and point out some essential characteristics of different models that contribute to the formation of positive or negative perfectionism.

\section{Concepts of Perfectionism}

To understand the concept of positive and negative perfectionism, the existing perfectionism models should be investigated. Several theories on types of perfectionism and several measurements have proved their validity and reliability to measure the specific types of perfectionism.

Although several multidimensional perfectionism constructs have been proposed, there are still one-dimensional models and measurements in use. For example, Perfectionism Cognitions Inventory (PCI) (Flett, Hewitt, Blankstein, \& Gray, 1998) based on the assumption that perfectionists, who sense a discrepancy between their actual self and the ideal self, or their level of goal attainment and high ideals will tend to experience automatic thoughts that reflect perfectionistic themes. What is unique about this concept is that it measures the frequency of perfectionistic thoughts and thus could be of use in cases where the need for achievement plays an important role, for example, in sport. It must be noted that this measurement alone would not clarify whether the perfectionistic thoughts contribute to the achievement and could be used as a resource or are to be viewed as pathological traits interfering with needed and wished-for achievement.

Following the idea of perfectionism as a positive or negative trait, several perfectionism models and their measurements are widely used, for example, Almost Perfect Scale-Revised (APS-R) (Slaney, Rice, Mobley, Trippi, \& Ashby, 2001) measuring: High Standards, Order, and Discrepancy and so distinguishing adaptive and maladaptive perfectionism. Features like High standards and Order are similarly pronounced in both positive and negative perfectionists, but what distinguishes them is high Discrepancy levels in negative perfectionists.

One of the three-dimensional perfectionism models widely used is the Multidimensional Perfectionism Scale (HFMPS) (Hewitt \& Flett, 2004). The three dimensions it is based on are Self-Oriented Perfectionism (high standards for the self), Other-Oriented Perfectionism (expecting others to be perfect), and Socially Prescribed Perfectionism (adopting high standards perceived as coming from others). Of all three, Socially prescribed perfectionism is particularly 
important in the research of wellbeing and health in society, showing the negative effect of perfectionism.

Another three-dimensional model developed recently is The Big Three Perfectionism Scale (Smith, Saklofske, Stoeber, \& Sherry, 2016). The three dimensions proposed in this model are Rigid perfectionism, Self-critical perfectionism, and Narcissistic perfectionism.

The $2 \times 2$ model of perfectionism states that rather than looking at distinct types of perfectionism, combinations of Self-oriented perfectionism and Socially prescribed perfectionism and four combinations among them: pure Self-orientated perfectionism, Mixed perfectionism, pure Socially prescribed perfectionism, and Non-perfectionism should be studied and taken into account in the outcomes of perfectionism (Gaudreau \& Thompson, 2010).

Another widely used model - The Frost Multidimensional Perfectionism model (FMPS) (Frost, Marten, Lahart, \& Rosenblate, 1990), consists of six dimensions: Personal Standards (setting self-determined high standards for personal performance), Concern Over Mistakes (a tendency to be overly critical of one's performance), Doubts About Actions (a tendency to have doubts about the quality of one's performance), Organization (emphasizing Order and precision), Parental Expectations (placing considerable value on parents' expectations), and Parental Criticism (putting significant weight on parents' disapproval and criticism) and proved itself to be of use in both personality and clinical psychology.

All of the models of perfectionism mentioned above have given their share in the research of perfectionism, allowing to measure the inherent type of perfectionism and its relationship to different variables, so investigating the adaptive or maladaptive nature of perfectionism.

\section{The Positive and Negative Aspects of Perfectionism}

Throughout its history, perfectionism has been studied a lot concerning psychological, emotional, and physical difficulties, and some adaptive aspects of perfectionism were pointed out as well. It is relatively straightforward that discussion about perfectionism's positive and negative aspects is needed.

As it is found in earlier works on perfectionism (see Hamachek, 1978; Hollender, 1965), maladaptive (or neurotic) perfectionists are characterized as the ones who set unattainably high standards, have exaggerated concerns over mistakes, and show almost no content or satisfaction with their performance or achievements. On the other hand, some perfectionists have high standards but are more flexible - able to adjust (Hamachek, 1978). 
Closer to nowadays, many studies and theories demonstrate a twodimensional understanding of perfectionism's nature, supporting previous theories on its adaptive and maladaptive features (see, Frost, Heimberg, Holt, Mattia, \& Neubauer, 1993; Slaney, Ashby, \& Trippi, 1995). Maladaptive perfectionism emphasizes the pathological aspects that are found to correlate to, for example, depressive symptoms, suicidal thoughts, rumination and anxiety (Rice, Ashby \& Slaney, 1998; Flett, Coulter, Hewitt, \& Nepon, 2011), negative affect in general (Hewitt \& Flett, 1991), and other undesirable outcomes. The adaptive dimension of perfectionism shows at least some positive aspects of perfectionism and is related to positive affect (see, Frost et al., 1993). On the contrary to pathological, so-called normal factors will be seen in those who set high but attainable standards, enjoy their performance, and overall tend to be more optimistic about future success (Enns, Cox, \& Clara, 2002). In similar studies, it was found that adaptive perfectionists experience less negative affect, lower levels of procrastination, higher levels of self-efficacy and self-esteem if compared to maladaptive perfectionists (see Lo \& Abbott, 2013; Slaney, Rice, Mobley, Trippi, \& Ashby, 2001). The concept of ability or inability to adapt is found in the work of Dunkley, Zuroff, and Blankstein (2003), supporting the idea of twodimensional perfectionism as Self-critical perfectionism and Personal Standards perfectionism. Self-critical perfectionism is described as constant and harsh selfscrutiny, overly critical evaluations of one's behaviour, an inability to derive satisfaction from successful performance, and chronic concerns about others' criticism and expectations, and Personal Standard's perfectionism typically involves the setting of high standards, where increased levels of stress may as well be experienced. However, these individuals tend to engage in active, problemfocused coping strategies (Dunkley, Zuroff, \& Blankstein, 2003). It was also proposed that perfectionistic strivings are a somewhat positive factor of perfectionism compared to unhealthy perfectionists and non-perfectionists. Furthermore, type of perfectionism plays an important role, as it is suggested that self-oriented perfectionists' strivings could be perceived as more positive, except that they are not overly concerned about mistakes and negative evaluations by others (Stoeber \& Otto, 2006). In the context of previous theories and findings, it may be concluded that perfectionism indeed is two dimensional, differing in the levels of ability to adapt.

The previous approaches tend to explain the dual nature of perfectionism. However, Slade and Owens went even further. They proposed the dual-process model of perfectionism, not just distinguishing a normal/healthy form and a pathological form of perfectionism, but also describing positive perfectionism as a predominantly normal and as the one that should be encouraged, thus in a way reflecting some principles of reinforcement attributable to positive perfectionism (Slade \& Owens, 1998). Interestingly enough, Flett and colleagues discussed a 
similar idea several decades later while trying to explain the persistence of perfectionism even though perfectionism is not attainable (in the meaning that the perfectionistic standards are not reachable). All it could bring to a person are aversive emotions, depressive affect, and lack of reward, which should be just the opposite of reinforcement and should decrease the frequency of perfectionistic behaviour, but it does not (Hewitt, Flett, \& Mikail, 2017). Perhaps, the effect of reinforcement could be paid more attention to in future studies.

Some scientists are very harsh critics of the idea of positive perfectionism as such. Even though at times, perfectionism may be perceived as an inner motivational force, it most likely arises from a wish to fulfil somebody else's desires or to avoid shame and guilt, as it is relatively straightforward that perfectionistic behaviour is the need of appreciation in the interaction with others, and as such is dependent (Greenspon, 2000). The fact that there is no positive side of perfectionism might be proved by four well-known facts: a) perfectionism is viewed as a risk factor for different psychopathologies (depression, eating disorders, etc.), b) high levels of perfectionism are often associated with various psychopathologies, c) perfectionism serves as an explanatory mechanism of a variety of psychopathologies and d) treated perfectionism reduces these psychopathologies (Egan, Wade, \& Shafran, 2011).

On the other hand, several studies, mostly in achievement studies, where perfectionism is regarded at least partly as a positive resource. Achievements in general and academic achievement, in particular, are believed to correlate with some aspects of perfectionism positively. Self-oriented perfectionism positively predicts mastery-approach and mastery-avoidance orientations. In contrast, socially prescribed perfectionism positively predicts performance-approach orientation (Damian, Stoeber, Negru, \& Baban, 2014a). It is also found that perfectionistic strivings potentially may promote academic achievement, and perfectionistic concerns potentially impair academic achievement in students (Madigan, 2019). Clarifying whether perfectionism should be a desirable trait at the workplace (striving for perfection could be something valued by the employer), it was concluded that perfectionism is not likely to be valuable behaviour. High levels of perfectionism could appear in the form of failure avoiding, and that does not exceed the supposed advantages (i.e., motivation, engagement) of perfectionism, as it has a mostly negative effect on mental wellbeing (Harari, Swider, Steed, \& Breidenthal, 2018).

It is possible to find some positive aspects of perfectionism that in a way promote achievement at work, academic achievement, achievement in sports or other areas by perfectionistic strivings, engagement, motivation (Harari, Swider, Steed \& Breidenthal, 2018). It also promotes higher levels of self-efficacy and self-esteem (Lo \& Abbott, 2019). However, on the other hand, it comes for the 
price that could be burnout (Garratt-Reed, Howell, Hayes, \& Boyes, 2018), depression and anxiety (Gnilka, \& Broda, 2019), eating disorders (Wade, O’Shea \& Shafran, 2016) and other negative effects of perfectionistic strivings.

\section{Conclusions}

The aim of the paper was to review studies focused on the mechanisms of perfectionistic representation, by looking into its threats to psychological wellbeing, caused by its pathological side, as well as, look into perfectionism as a possible resource for personal growth and achievement.

The mechanisms behind perfectionistic representation can be explained by its aetiology - the early interaction with caregivers and the necessity of attachment in the form that is possible in the given circumstances and environment and also by genetic predisposition. The form of interaction with early caregivers impacts the type of perfectionism being formed. There are several concepts of perfectionism and each has contributed to explaining perfectionistic behaviour and difficulties arising from it.

Most theories and studies insist on the dual nature of perfectionism. However, its negative consequences prevail over its possible positive outcomes, perhaps, because the negative consequences are indeed pathological (for example, depression, anxiety, suicidal thoughts), whether positive outcomes are mostly seen as some form of achievement.

It should also be noted that complex research involving several perfectionism constructs and possibly personality traits is needed to distinguish if and what combinations of perfectionism and personality traits contribute to perfectionism's positive and negative outcomes. Several aspects mentioned in this study may also be helpful in providing psychological support for perfectionists, as it clarifies the aetiology and positive and negative aspects of perfectionism,

As the limitations of this study must be mentioned, perfectionism is predominately studied using quantitative methods, but several qualitative studies are worth looking into, of which only a few were mentioned here.

\section{References}

Adler, A. (1956). The Individual Psychology of Alfred Adler, H. L. Ansbacher \& R. R. Ansbacher (Eds.). New York, NY: Harper Torchbooks.

Cruce, S. E., Pashak, T. J., Handal, P. J., Munz, D. C., \& Gfeller, J. D. (2012). Conscientious Perfectionism, Self-Evaluative Perfectionism, and the Five-Factor Model of personality traits. Personality and Individual Differences, 53(3), 268-273. https://doi.org/ 10.1016/j.paid.2012.03.013 
Curran, T., \& Hill, A. P. (2019). Perfectionism is increasing over time: A meta-analysis of birth cohort differences from 1989 to 2016. Psychological Bulletin, 145(4), 410-429. https://doi.org/10.1037/bul0000138

Damian, L.E., Stoeber, J., Negru, O., \& Baban, A. (2013). On the development of perfectionism in adolescence: Perceived parental expectations predict longitudinal increases in socially prescribed perfectionism. Personality and Individual Differences, 55(6), 688-693. https://doi.org/10.1016/j.paid.2013.05.021

Damian, E., Stoeber, J., Negru, O., \& Baban, A. (2014a). Perfectionism and achievement goal orientation in adolescent school students. Psychology in the Schools, 51(9), 960-971. https://doi.org/ 10.1002/pits.21794

Damian, E., Stoeber, J., Negru, O., \& Baban, A. (2014b). Positive and negative affect in adolescents: An investigation of the $2 \times 2$ model of perfectionism. Cognition, Brain, Behavior. An Interdisciplinary Journal, 18(1), 1-16.

Dunkley, D. M., Zuroff, D. C., \& Blankstein, K. R. (2003). Self-critical perfectionism and daily affect: Dispositional and situational influences on stress and coping. Journal of Personality and Social Psychology, 84(1), 234-252. https://doi.org/10.1037/00223514.84.1.234

Egan, S. J., Wade, T. D., \& Shafran, R. (2011). Perfectionism as a transdiagnostic process: A clinical review. Clinical Psychology Review, 31, 203-212. https://doi.org/10.1016/ j.cpr.2010.04.009

Enns, M. W., Cox, B. J., \& Clara, I. (2002). Adaptive and maladaptive perfectionism: Developmental origins and association with depression proneness. Personality and Individual Differences, 33(6), 921-935. https://doi.org/10.1016/S0191-8869(01)00202-1

Flett, G. L., Hewitt, P. L., Oliver, J. M., \& Macdonald, S. (2002). Perfectionism in children and their parents: A developmental analysis. In G. L. Flett \& P. L. Hewitt (Eds.), Perfectionism: Theory, research, and treatment (pp. 89-132). Washington, DC, US: American Psychological Association. http://dx.doi.org/10.1037/10458-004

Flett, G. L., Coulter, L.M., Hewitt, P. L., \& Nepon, T. (2011). Perfectionism, rumination, worry, and depressive symptoms in early adolescents. Canadian Journal of School Psychology, 26(3), 159-176. https://doi.org/10.1177/0829573511422039

Flett, G. L., Hewitt, P. L., Blankstein, K. R., \& Gray, L. (1998). Psychological distress and the frequency of perfectionistic thinking. Journal of Personality and Social Psychology, 75(5), 1363-1381. https://doi.org/10.1037/0022-3514.75.5.1363

Flett, G. L., \& Hewitt, P. L. (2002). Perfectionism and maladjustment: An overview of theoretical, definitional, and treatment issues. In G. L. Flett \& P. L. Hewitt (Eds.), Perfectionism: Theory, research, and treatment (p. 5-31). American Psychological Association. https://doi.org/10.1037/10458-001

Frost, R. O., Marten, P., Lahart, C., \& Rosenblate, R. (1990). The dimensions of perfectionism. Cognitive Therapy and Research, 14(5), 449-468. https://doi.org/10.1007/BF01172967

Frost, R. O., Heimberg, R. G., Holt, C. S., Mattia, J. I., \& Neubauer, A. L. (1993). A comparison of two measures of perfectionism. Personality and Individual Differences, 14(1), 119126. https://doi.org/10.1016/0191-8869(93)90181-2

Gabbard, G. O. (2004). Long-term psychodynamic psychotherapy: A basic text. Washington, DC: American Psychiatric Association.

Garratt-Reed, D., Howell, J., Hayes, L. \& Boyes, M. (2018). Is perfectionism associated with academic burnout through repetitive negative thinking? PeerJ, 6. https://doi.org/ 10.7717/peerj.5004 
Gilman, R., \& Ashby, J. S. (2003). A first study of perfectionism and multidimensional life satisfaction among adolescents. The Journal of Early Adolescence, 23(2), 218-235. https://doi.org/10.1177/0272431603023002005

Gaudreau, P., \& Thompson, A., (2010). Testing a $2 \times 2$ model of dispositional perfectionism. Personality and Individual Differences, 48(5), 532-537.

Gnilka, P., McLaulin, S., Ashby, J. \& Allen, M. (2017). Coping Resources As Mediators Of Multidimensional Perfectionism And Burnout. Consulting Psychology Journal: Practice and Research. 69. https://doi.org/10.1037/cpb0000078.

Gnilka, P., Broda, M.D., (2019). Multidimensional perfectionism, depression, and anxiety: Tests of a social support mediation model. Personality and Individual Differences, 139 (1), 295-300. https://doi.org/10.1016/j.paid.2018.11.031.

Greenspon, T.S. (2000). "Healthy Perfectionism" is an Oxymoron!: Reflections on the Psychology of Perfectionism and the Sociology of Science. Journal of Advanced Academics, 11(4), 197-208. https://doi.org/10.4219/jsge-2000-631

Greenspon, T.S. (2008). Making Sense of Error: A View of the Origins and Treatment of Perfectionism. American Journal of Psychotherapy 62(3), 263-82. https://doi.org/ 10.1176/appi.psychotherapy.2008.62.3.263

Hamachek, D. E. (1978). Psychodynamics of normal and neurotic perfectionism. Psychology: A Journal of Human Behavior, 15(1), 27-33. https://doi.org/10.1037/cpb0000078

Harari, D., Swider, B. W., Steed, L. B., \& Breidenthal, A. P. (2018). Is perfect good? A metaanalysis of perfectionism in the workplace. Journal of Applied Psychology, 103(10), 1121-1144. https://doi.org/10.1037/apl0000324

Hewitt, P., \& Flett, G. (1989). The Multidimensional Perfectionism Scale: Development and validation. Canadian Psychology, 30, pp 339.

Hewitt, P. L., \& Flett, G. L. (1991). Perfectionism in the self and social contexts: Conceptualization, assessment, and association with psychopathology. Journal of Personality and Social Psychology, 60(3), 456-470. https://doi.org/10.1037/00223514.60.3.456

Hewitt, P. L., \& Flett, G. L. (2004). Multidimensional Perfectionism Scale (MPS): Technical manual. Toronto, Canada: Multi-Health Systems.

Hewitt, P. L., Flett, G. L., Sherry, S. B., \& Caelian, C. (2006). Trait Perfectionism Dimensions and Suicidal Behavior. In T. E. Ellis (Ed.), Cognition and suicide: Theory, research, and therapy (pp. 215-235). Washington, DC, US: American Psychological Association. http://doi.org/10.1037/11377-010

Hewitt, P. L., Flett, G. L., \& Mikail, S. F. (2017). Perfectionism: A relational approach to conceptualization, assessment, and treatment. The Guilford Press.

Hollender, M. H. (1965) Perfectionism. Comprehensive Psychiatry, 6(2), 94-103

Horney, K. (1950). Neurosis and Human Growth. New York: Norton.

Lo, A. \& Abbott, M.J. (2019). Self-concept certainty in adaptive and maladaptive perfectionists. Journal of Experimental Psychopathology, 10(2), https://doi.org/10.1177/ 2043808719843455

Madigan, D.J. (2019). A Meta-Analysis of Perfectionism and Academic Achievement. Educational Psychology, 31, 967-989. https://doi.org/10.1007/s10648-019-09484-2

Maslow, A. H. (1970). Motivation and personality. New York: Harper \& Row.

Missildine, W. H. (1991).Your Inner Child of the Past. Simon \& Schuster.

Rice, K. G., Ashby, J. S., \& Slaney, R. B. (1998). Self-esteem as a mediator between perfectionism and depression: A structural equations analysis. Journal of Counseling Psychology, 45(3), 304-314. https://doi.org/10.1037/0022-0167.45.3.304 
Rothstein, A. (1991). On some relationships of fantasies of perfection to the calamities of childhood. International Journal of Psychoanalysis, 72(2), 313-323.

Slade, P. D., \& Owens, R. G. (1998). A dual process model of perfectionism based on reinforcement theory. Behavior Modification, 22, 372-390. https://doi.org/ $10.1177 / 01454455980223010$

Slaney, R. B., Ashby, J. S., \& Trippi, J. (1995). Perfectionism: Its measurement and career relevance. Journal of Career Assessment, 3(3), 279-297. https://doi.org/ $10.1177 / 106907279500300403$

Slaney, R.B., Rice, K.G., Mobley, M., Trippi, J., \& Ashby, J.S. (2001). The Revised Almost Perfect Scale. Measurement and Evaluation in Counseling and Development 34(3),130145. https://doi.org/10.1080/07481756.2002.12069030

Slaney, R. B., Rice, K. G., \& Ashby, J. S. (2002). A programmatic approach to measuring perfectionism: The Almost Perfect Scales. In G. L. Flett \& P. L. Hewitt (Eds.), Perfectionism: Theory, research, and treatment (p. 63-88). American Psychological Association. https://doi.org/10.1037/10458-003

Smith, M. M., Saklofske, D. H., Stoeber, J. \& Sherry, S.B. (2016). The Big Three Perfectionism Scale: A New Measure of Perfectionism. Journal of Psychoeducational Assessment, 3(7), 670-687. https://doi.org/10.1177/0734282916651539

Smith, M. M., Saklofske, D. H., Yan, G., \& Sherry, S. B. (2017). Does perfectionism predict depression, anxiety, stress, and life satisfaction after controlling for neuroticism? A study of Canadian and Chinese undergraduates. Journal of Individual Differences, 38(2), 6370. https://doi.org/10.1027/1614-0001/a000223

Speirs-Neumeister, K.L. (2004). Understanding the Relationship Between Perfectionism and Achievement Motivation. Gifted Child Quarterly, 48(3), 219 - 231. https://doi.org/10.1177/001698620404800306

Speirs-Neumeister, K.L., Williams, K.K., \& Cross, T.L. (2009). Gifted High-School Students' Perspectives on the Development of Perfectionism. Roeper Review, 31(4), 198 - 206. https://doi.org/10.1080/02783190903177564

Stoeber, J., \& Otto, K. (2006). Positive Conceptions of Perfectionism: Approaches, Evidence, Challenges. Personality and Social Psychology Review, 10(4), 295-319. https://doi.org/10.1207/s15327957pspr1004_2

American Psychiatric Association. (2000). The Diagnostic and Statistical Manual of Mental Disorders (DSM-5).

Wade, T., O’Shea, A., \& Shafran, R. (2016). Perfectionism and Eating Disorders. In: Sirois F., Molnar D. (eds), Perfectionism, Health, and Well-Being. Springer, Cham. https://doi.org/10.1007/978-3-319-18582-8_9 